\title{
Stem cells and periodontal regeneration: present and future
}

\author{
Filippo Citterio, Giacomo Gualini, Ludovica Fierravanti, Mario Aimetti \\ Department of Surgical Sciences, Periodontology, C.I.R. Dental School, Turin 10126, Italy.
}

Correspondence to: Dr. Filippo Citterio, Department of Surgical Sciences, Periodontology, C.I.R. Dental School, Turin 10126, Italy. E-mail: filippo.citterio@unito.it

\begin{abstract}
How to cite this article: Citterio F, Gualini G, Fierravanti L, Aimetti M. Stem cells and periodontal regeneration: present and
\end{abstract} future. Plast Aesthet Res 2020;7:41. http://dx.doi.org/10.20517/2347-9264.2020.29

Received: 20 Feb 2020 First Decision: 6 May 2020 Revised: 17 Jun 2020 Accepted: 28 Jun 2020 Published: 15 Aug 2020

Academic Editor: Yi-Lin Cao Copy Editor: Cai-Hong Wang Production Editor: Jing Yu

\begin{abstract}
The ultimate goal of periodontal regeneration is to restore the damaged alveolar bone proper, root cementum, and periodontal ligament with collagen fibers inserted into the root surface. The search for new regenerative strategies is a challenging field of periodontal research, and tissue engineering, using stem cells, has recently been shown as a promising approach. This paper aims at reviewing the current available literature on the use of stem cells for the treatment of periodontitis. Up to now, different mesenchymal stem cells (MSCs) have shown potential for periodontal regeneration in animal studies. The most investigated MSCs for periodontal regeneration are bone marrow MSCs (BMMSCs), periodontal ligament stem cells (PDLSCs), and dental pulp stem cells (DPSCs), which have shown very promising results in animal models. Few studies on humans are available but BMMSCs, PDLSCs, and DPSCs have been proven safe and effective. Clinical trials are sparse, but tend to support the efficacy of MSCs for periodontal regeneration. In the future, more human studies will be required to support the use of MSCs in daily clinical practice, especially in order to identify the best protocol to harvest, process, and graft MSCs. Future perspectives include trans-differentiation of somatic cells to generate induced pluripotent stem cells, homing procedures, the use of exogenous stem cells, and 3D-printed scaffolds.
\end{abstract}

Keywords: Stem cells, regeneration, periodontology, tissue engineering, bone defects

\section{INTRODUCTION}

Stem cells and tissue engineering have recently been introduced into the field of periodontology and they have shown encouraging potential in the treatment of periodontitis, which is a complex immune- 
inflammatory disease, characterized by the loss of periodontal tissues around teeth and by the formation of periodontal pockets (PD). In susceptible individuals, periodontitis occurs when the inflammatory and immune response to the microbial challenge of dental plaque is dysregulated. If left untreated, periodontitis may progress at different rates and eventually lead to tooth loss, especially in a sub-fraction of patients who may be highly susceptible.

Periodontitis affects the majority of the adult population ${ }^{[1,2]}$, may cause edentulism, and has been listed as a risk factor for major systemic diseases, such as atherosclerosis, cardiovascular diseases ${ }^{[3]}$, diabetes ${ }^{[4]}$, and rheumatoid arthritis ${ }^{[5,6]}$. This may directly influence the general health, social life, and nutritional state of affected individuals, jeopardizing their overall quality of life $\mathrm{f}^{[7-10]}$. Moreover, the treatment of advanced forms of periodontitis is expensive, with a direct impact on Western countries' productivity, thus making periodontitis a threat for public health ${ }^{[11]}$.

Periodontal treatment aims to control inflammation in the periodontal tissues, avoiding disease progression, preserving natural teeth, and maintaining masticatory function. To achieve these goals, the treatment is focused on reducing or eradicating PDs. Many non-surgical and surgical approaches are currently used. Non-surgical periodontal therapy is the first step for any patient affected with periodontitis. The desegregation of the bacterial biofilm at PD sites provides a reduction of PDs and inflammation, especially in $\mathrm{PDs} \leq 6 \mathrm{~mm}^{[12,13]}$. If the number of residual pockets is limited and inflammation is under control, patients are expected to experience limited tooth loss $\left(0.1\right.$ tooth/patient/year $\left.{ }^{[14]}\right)$ throughout a lifelong supportive care program, which is generally enough to prevent masticatory dysfunction. However, patients who still present multiple PDs $\geq 5 \mathrm{~mm}$, or even one PD $\geq 6 \mathrm{~mm}$ after non-surgical therapy, take significant risk to experience disease progression and require additional surgical treatment ${ }^{[15,16]}$ with the goals: (1) to provide access to root surface; and (2) to arrest disease progression by reducing PDs. Surgical treatment of periodontitis includes non-resective access surgery, resective surgery, and regenerative procedures. Non-resective surgery aims at facilitating root debridement by means of flap elevation. Different techniques have been proposed and minimally-invasive approaches have shown advantages in clinical trials ${ }^{[17]}$. Resective surgery eradicates PD by correcting gingival and bone morphology. Although extremely effective against PDs, it is carried out at the expense of the periodontal support of the involved teeth and invariably causes soft tissue recession ${ }^{[1,19]}$. Periodontal regeneration has the goal to restore the lost periodontium, as it aims at increasing the periodontal attachment, reducing PD, and limiting gingival recession. This makes periodontal regeneration the gold standard for periodontal treatment ${ }^{[20]}$.

Periodontal regeneration has been shown to be effective in the treatment of intrabony and furcation defects with varying degrees of efficacy ${ }^{[2,22]}$; however, regenerative procedures are still exposed to clinical failures or incomplete success due to various limitations, such as patient-specific factors (i.e., smoking, poor plaque control, etc.), improper choice of access flaps and biomaterials, and poor periodontal training ${ }^{[23]}$. Alveolar bone proper, root cementum, and periodontal ligament (PL) in the previously damaged periodontium are expected to be regenerated as the ideal treatment outcome, but it has been shown to not always be the case $^{[24]}$. To overcome these limitations, new access flaps ${ }^{[25-28]}$ and biological agents ${ }^{[29,30]}$ have been developed in recent years; clinical trials, however, have revealed a still controversial efficacy and their histological evidence is generally sparse. Thus, the search for new regenerative procedure is still a challenging field of periodontal research. In this context, tissue engineering ${ }^{[31]}$, cell combination, biomaterials, and growth factors have recently been proposed as promising alternatives for periodontal treatment. In this field, stem cells are attractive. They are undifferentiated cells that possess regenerative potential thanks to their ability to develop into different cell types after proper stimulation ${ }^{[32]}$. In periodontal regeneration, mesenchymal stem cells (MSCs) have been tested in vitro and in humans with promising results ${ }^{[33]}$. MSCs from dental and non-dental tissues have been harvested and used ${ }^{[34]}$. Among MSCs from dental tissue, we may list dental pulp stem cells (DPSCs $)^{[35]}$, human exfoliated deciduous teeth cells $\left(\right.$ SHEDs ${ }^{[36]}$, periodontal ligament stem 
cells (PDLSCs) ${ }^{[37]}$, dental follicle precursor cells (DFPCs) ${ }^{[38]}$, and stem cells from apical papilla (SCAPs) ${ }^{[39]}$. Various non-dental stem cells have been used in periodontal regeneration. Among others, BMMSCs, adipose-derived stem cells (ASCs), embryonic stem cells (ESCs), and induced pluripotent stem cells (iPSCs) have been the most investigated.

Evidence of which is the most effective protocol is still lacking. Thus, the primary aim of this review is to summarize the available scientific evidence about periodontal regeneration using MSCs. Clinical and histological outcomes of periodontal regeneration are reviewed and synthesized.

\section{MESENCHYMAL STEM CELLS FOR PERIODONTAL REGENERATION}

\section{Dental stem cells}

Dental Stem Cells (DSCs) are multi-potent, self-renewing MSCs. DSCs may differentiate toward osteogenic, odontogenic, dentinogenic, cementumogenic, adipogenic, chondrogenic, myogenic, and neurogenic lineages. DSCs are easily accessible since they may be found in the human body at all ages. Furthermore, cryopreservation does not affect their properties ${ }^{[40]}$. These characteristics make them accessible and easy to handle.

DPSCs were among the first DSCs isolated. They are easily accessible in large number because they can be obtained from human dental pulp. DPSCs are especially attractive for a plethora of reasons. First, they are found in dental pulp and their harvesting only requires an extracted tooth, including third molars and periodontally compromised teeth. It has also been speculated that they can be obtained from dental pulp with inflammation ${ }^{[41]}$ and still show potential to differentiate into osteoblast-like cells. Second, DPSCs share origin, antigenic pattern, and differentiation lineages with periodontal stem cells ${ }^{[35,40,41]}$. Furthermore, they can also differentiate in other cell types including cardio-myocytes, neuron cells, adipocytes, corneal epithelial cells, melanoma cells, and insulin secreting Beta cells ${ }^{[42]}$. Third, they easily interact with

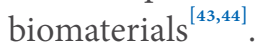

PDLSCs have been considered ideal candidates for periodontal regeneration since they can be easily recovered by non-invasive procedures after simple tooth extraction. In addition, they can be cultured. PDLSCs are known to possess osteogenic, chondrogenic, and adipogenic potential and exhibit immunosuppressive characteristics similar to those described for bone marrow MSCs (BMMSCs) and DPSCs. They possess the ability to form a cementum/PL complex-like structure.

SHEDs are easy to access by using noninvasive procedures, as they are harvested from deciduous exfoliated teeth. SHEDs exhibit a high rate of proliferation and immuno-modulatory properties, similar to those of BMMSCs, which are comparatively more difficult to harvest. They are able to differentiate into osteoblasts $^{[45]}$ and could express an immuno-regulatory potential on T cells, macrophages, and dendritic cells $^{[46]}$. Nakamura et al ${ }^{[4]}$ compared the "stemness" of SHEDs to DPSCs and BMMSCs and noticed that SHEDs revealed a higher proliferation rate than DPSCs and BMMSCs and higher expression of genes of cell proliferation and extracellular matrix elements. This makes this cell type an interesting candidate for periodontal regeneration.

DFPCs may act as precursor cells for PDLSCs. DFPCs are able to enhance the proliferation and osteogenic and adipogenic differentiation of PDLSCs to different degrees. Co-culture with DFPCs increases cell layers and extracellular matrix of PDLSC cell sheets in vitro ${ }^{[48]}$. However, scientific evidence for this cell type is still limited.

SCAPs are related to developing roots. Their presence in the apical papilla of forming roots has been suggested as a possible explanation of how immature teeth with necrotic pulps are able to undergo 
root development. SCAPs have infection-resistant properties too ${ }^{[49]}$, and this may further explain why apexogenesis has been observed even in the presence of apical periodontitis. Despite being difficult to collect, they are a promising tool for regenerative procedures as they have multi-lineage differentiation potential $^{[50]}$.

\section{Non-dental stem cells}

BMMSCs were the first MSCs discovered and have been extensively tested more often on animal models. They have shown osteogenic, adipogenic, chondrogenic, and myogenic differentiation. The major shortcoming of BMMSCs is the pain of the bone marrow harvesting and the limited quantities that can be collected. BMMSCs can differentiate into ameloblast-like cells ${ }^{[51,52]}$ and periodontal tissue cells and can enhance periodontal regeneration ${ }^{[3,54]}$. Interestingly, besides periodontal regeneration, BMMSCs may be used for tooth regeneration as they can upregulate the expression of odontogenic genes and contribute to new tooth formation after recombination with embryonic oral epithelium ${ }^{[55]}$.

ASCs are stem cells derived from adipose tissues and are abundant. ASCs allow in vitro expansion and have undergone osteogenic, chondrogenic, adipogenic, and neurogenic differentiation in various experimental settings. The harvesting method is less invasive than the method used for BMMSCs, since ASCs may be retrieved in high number from either liposuction or subcutaneous adipose tissue fragments. For this reason, they have been extensively used in regenerative medicine.

ESCs are pluripotent stem cells found in human blastocysts. They show an extraordinary potential for differentiation as they can develop into almost all cell lineages ${ }^{[56]}$. In the context of periodontal research, it has been shown that ESCs can differentiate into odontogenic and periodontal cell lineages, in particular if co-cultured with PDLSCs or embryonic oral epithelium cell ${ }^{[57,58]}$. Ethical concerns have hampered the use of such cells for periodontal regeneration since their harvesting may result in the destruction of human blastocysts. Furthermore, besides their unlimited potential, they have shown major adverse effects such as tumors and unwanted immune responses.

iPSCs were first discovered in 2006 and have since generated substantial interest in regenerative medicine ${ }^{[59]}$. They are a type of pluripotent stem cell that can be generated directly from a somatic cell. They can duplicate indefinitely, as well as give rise to every other cell type in the body. Recently, dental cells including DPSCs, SHEDs, PDLSCs, and SCAPs have been successfully reprogrammed into iPSCs ${ }^{[60,61]}$, and iPCSs have been investigated for periodontal regeneration.

\section{ANIMAL STUDIES}

Before testing the performance of the use of stem cells in humans, its feasibility and safety have always been proven in animal studies. Up to now, more than 2000 articles that used stem cells for regeneration of both tooth and dental supporting tissues on animal models have been listed in MEDLINE. The main animal models used are dogs, mini-pigs, rats, and sheep.

All different types of stem cells have been tested with several approaches (e.g., different isolation processes, different implantation methods, etc.) with promising results in terms of regeneration of bone and dental supporting tissues (PL and root cementum $)^{[62,63]}$. Although promising, from all these studies, no clear clinical protocol can be ultimately validated due to the heterogeneity of the investigation designs and because we still do not have a complete understanding of how these cells interact in the healing and regenerative processes [Tables 1 and 2]. Of course, more studies are needed to elucidate these aspects in greater details and better select a stem cell-based protocol for periodontal regeneration. Different results among studies can be ascribed to the different protocols used. The main differences that play an important role in the outcomes are the characteristics of the donor, especially age ${ }^{[64]}$; the isolation and expansion 
Table 1. Summary of available evidence for periodontal regeneration with mesenchymal stem cells

\begin{tabular}{|c|c|c|c|}
\hline & Bone regeneration & PL & Cementum \\
\hline BMMSC & $\begin{array}{l}\text { Effective in grade III furcation defects, } \\
\text { but bone fill is not complete; } \\
\text { Ineffective when used without bone } \\
\text { substitutes }\end{array}$ & $\begin{array}{l}\text { Effective in grade III furcation defects; } \\
\text { Conflicting results; effective only } \\
\text { associated with bone substitutes }\end{array}$ & Effective in grade III furcation defects \\
\hline ASC & Effective in extraction sockets & $\begin{array}{l}\text { Effective in surgically created intrabony } \\
\text { defects }\end{array}$ & $\begin{array}{l}\text { Effective in surgically created intrabony } \\
\text { defects }\end{array}$ \\
\hline PDLSC & $\begin{array}{l}\text { Effective in fenestration; No added } \\
\text { benefit associated with non reservable } \\
\text { membranes in fenestrations; Effective } \\
\text { in intrabony defects only using bone } \\
\text { substitutes }\end{array}$ & $\begin{array}{l}\text { Effective in fenestration; More effective } \\
\text { than BMMSC; } \\
\text { Effective in intrabony defects with better } \\
\text { results using bone substitutes }\end{array}$ & $\begin{array}{l}\text { Effective in fenestration; added } \\
\text { benefit associated with non reservable } \\
\text { membranes in fenestrations: Effective } \\
\text { in intrabony defects with better results } \\
\text { using bone substitutes }\end{array}$ \\
\hline DPSC & $\begin{array}{l}\text { Effective in extraction sockets; Improve } \\
\text { bone regeneration in intrabony defects }\end{array}$ & $\begin{array}{l}\text { Improve regeneration in intrabony } \\
\text { defects }\end{array}$ & $\begin{array}{l}\text { Improve regeneration in intrabony } \\
\text { defects }\end{array}$ \\
\hline DFPC & Improve effects of PDLSC & Improve effects of PDLSC & Improve effects of PDLSC \\
\hline SHED & $\begin{array}{l}\text { Increased bone volume in intrabony } \\
\text { defects }\end{array}$ & Increased PL fibers in intrabony defects & Increased in intrabony defects \\
\hline SCAP & $\begin{array}{l}\text { Increased bone volume in intrabony } \\
\text { defects compared to saline }\end{array}$ & $\begin{array}{l}\text { Increased in intrabony defects compared } \\
\text { to saline }\end{array}$ & $\begin{array}{l}\text { Increased in intrabony defects compared } \\
\text { to saline }\end{array}$ \\
\hline
\end{tabular}

BMMSC: bone marrow mesenchymal stem cell; ASC: adipose-derived stem cell; PDLSC: periodontal ligament stem cell; DPSC: dental pulp stem cell; DFPC: dental follicle precursor cell; SHED: stem cell from human exfoliated teeth; SCAP: stem cell from apical papilla

methods ${ }^{[65]}$; the way of delivery and implantation in combination with membranes ${ }^{[66]}$; and biomaterials ${ }^{[67,68]}$ or bioactive molecules ${ }^{[69,70]}$.

Briefly, age has no effect on the possibility of isolating and culturing stem cells, but showed a statistically significant effect on the procedure outcome. Cells harvested from donors over 60 years of age had an over $50 \%$ failure rate. On the contrary, in younger donors ( $\leq 60$ years old), the failure rate ranged between $14 \%$ and $22 \%$. No effect of gender was found, with similar success rates for male and female donors ${ }^{[64]}$.

It has been suggested that the site of harvesting can also influence the outcomes of the cell therapy procedures, according to the differences found in stem cells of the same lineage but taken from different niches. More studies are needed to confirm this finding ${ }^{[64]}$.

The culture and the expansion protocols used to amplify the numbers of transplanted cells are a variable that can alter the "stemness" properties of the stem cells. No clear protocol has been developed yet for the treatment of MSCs, in particular oral ones. We know that under certain conditions (i.e., particular culture mediums) we can alter the differentiation path, favoring a subset of cells that can increase the successful outcomes of our cell treatments ${ }^{[7]}$; however, further research is needed to better understand and guide this process.

Finally, the protocols wherewith these cells are administered can have a positive or negative effect on the final result. Cell therapy can be administered on a scaffold base or on a scaffold-free delivery system. The first one implies the use of a biomaterial, usually calcium-based, a membrane, or a combination of the two. The rational behind the use of biomaterials and membranes is the need for blood clot stability in order to reach its formation and maturation. When the conformation of the periodontal defect is not firm enough, biomaterials and membranes can make up for the lack of stability and enhance the regeneration process. It has been shown, also in vivo, that different materials have different effects, either positive or negative, on the non-cell-based regeneration techniques ${ }^{[30]}$. Similarly, these effects have been found in cellbased regenerative therapies, with promising results from beta- $\mathrm{TCP}^{[46,72-74]}$, hyaluronic $\operatorname{acid}^{[75,76]}$, and nano designed materials ${ }^{[77-79]}$. 


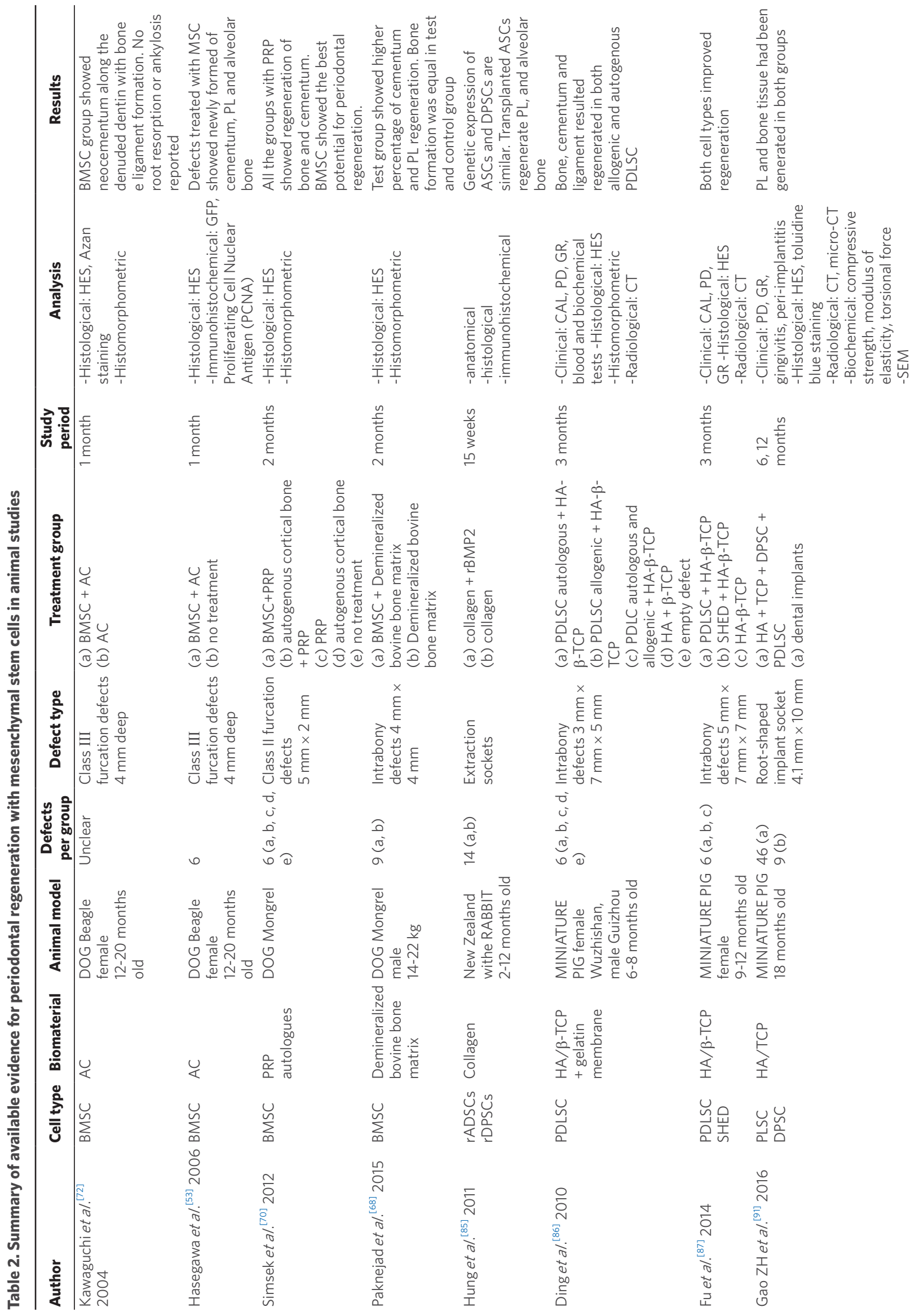



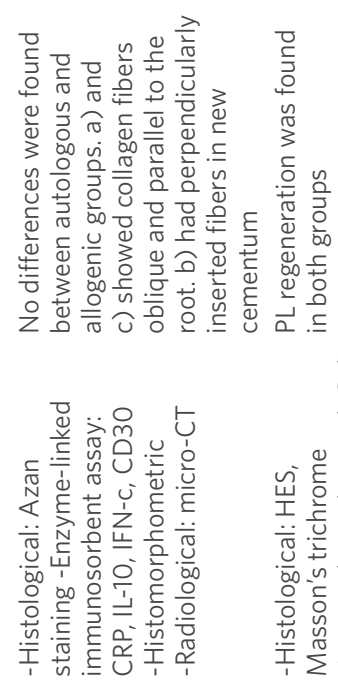

$\stackrel{n}{\frac{n}{ \pm}}$

$+$

苍

帘

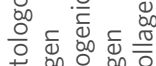

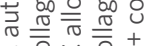

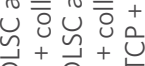

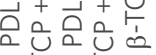

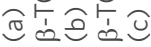

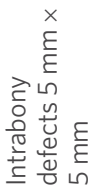

0
$\infty$
กั
$\infty$

$\frac{0}{20}$
ه
0
0
0
0

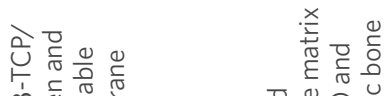

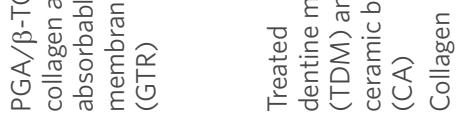

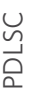

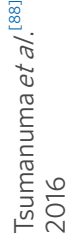

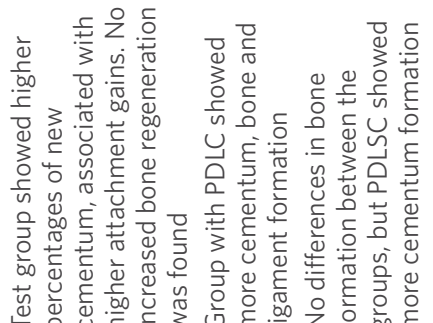

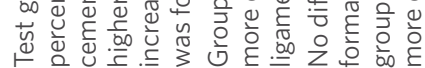
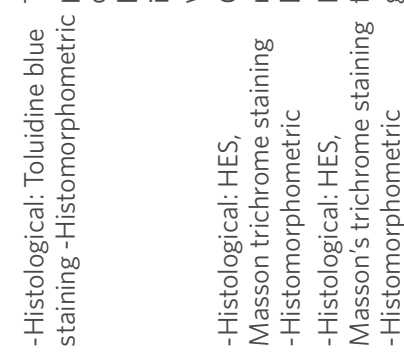

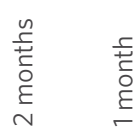

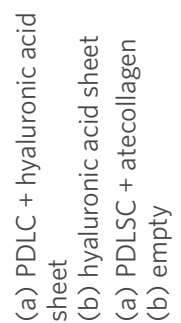

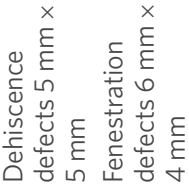

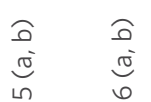

$\frac{0}{80} \frac{0}{0} \frac{0}{80}$

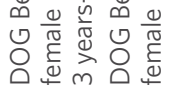

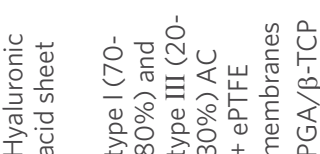

$\stackrel{u}{\cup} \stackrel{\cup}{a}$

$\stackrel{\cup}{a}$

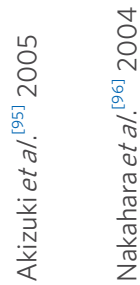

$\underset{\substack{0 \\ \text { o }}}{0}$

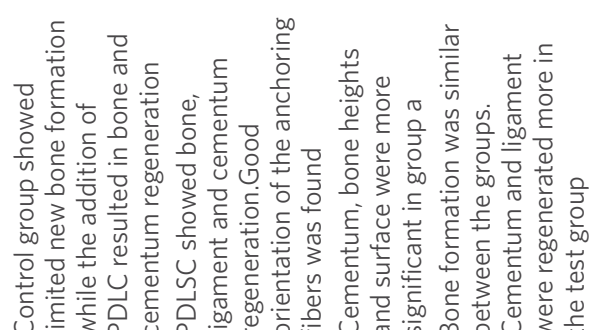

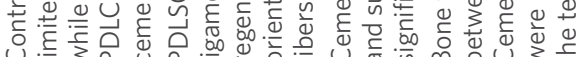

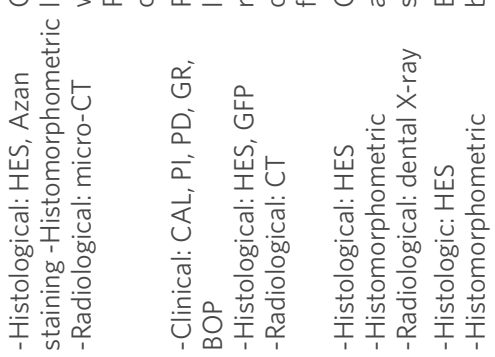

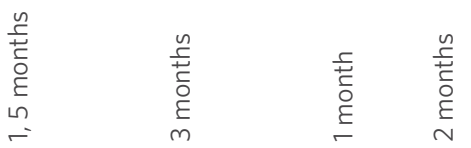

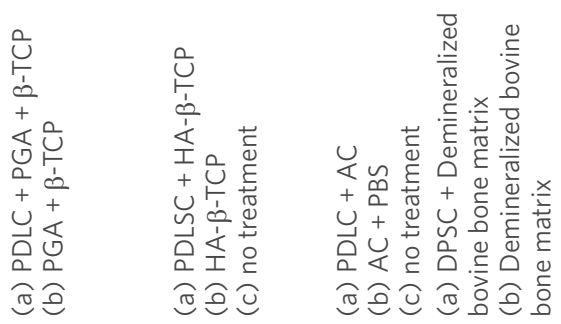

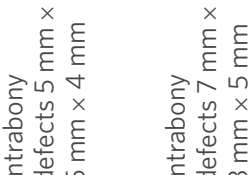

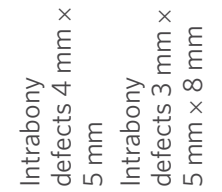

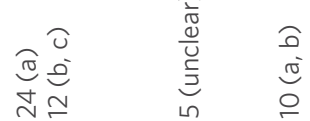

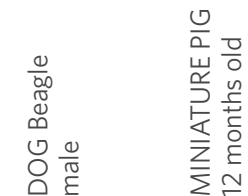

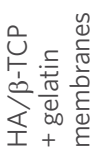

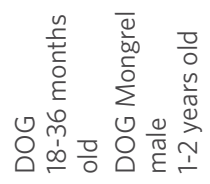

\section{ù}

ư

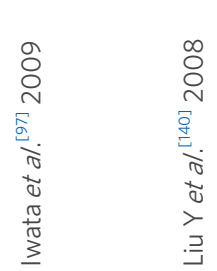

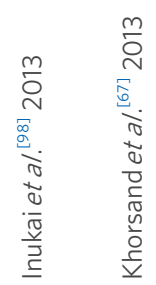




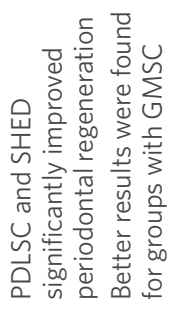

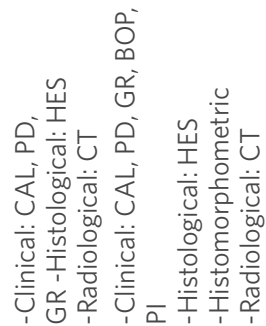

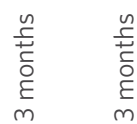

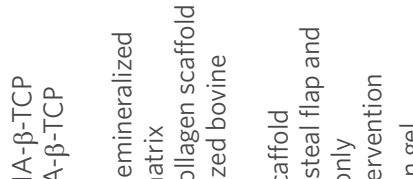

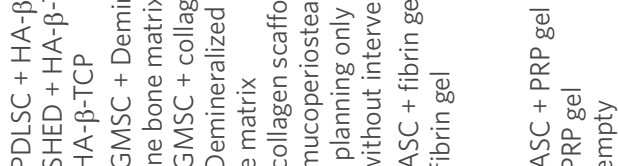

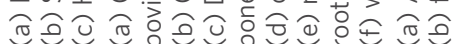

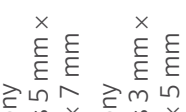

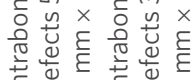

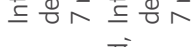

o

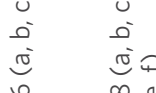

늠 흥읏 긍

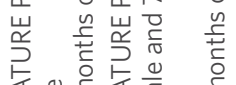

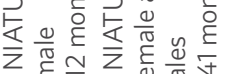

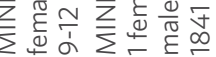

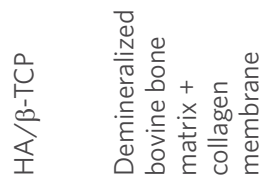

岂崖 $\sum_{0}^{u}$

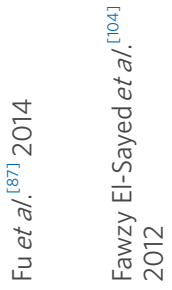

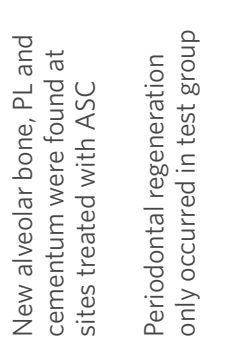

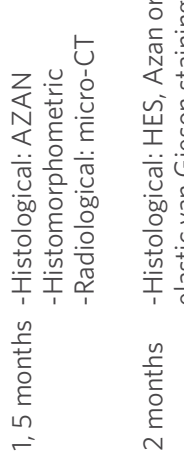

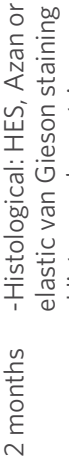

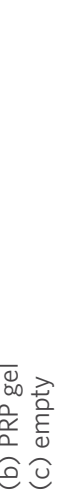

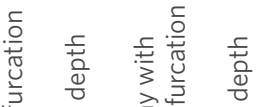

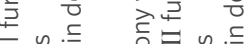

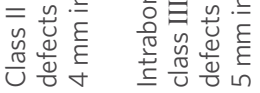
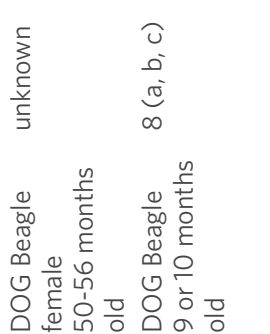

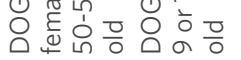

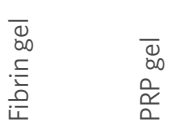

选雚

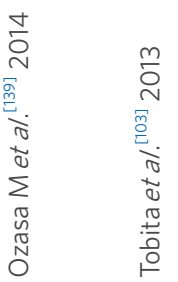

\section{(a)}

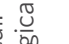

政

0
0

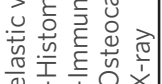

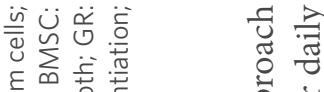

부요 $\cong \Xi$

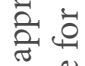

站这

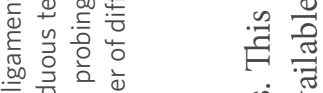

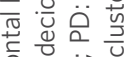

을 뭉

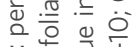

议进亭

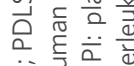

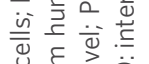

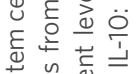

월

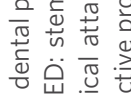

记岌航

产完安

है

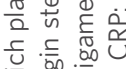

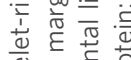

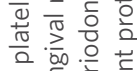

$\therefore$ व.

这苍获

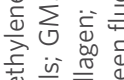

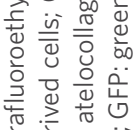

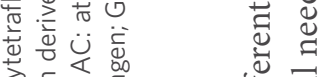

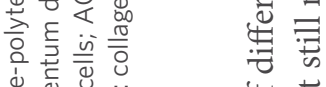

نं हैं

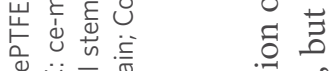

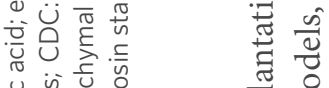

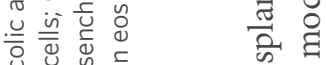

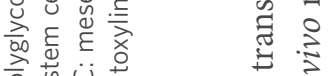

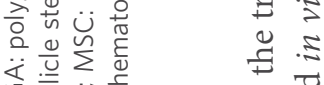

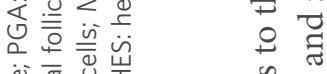

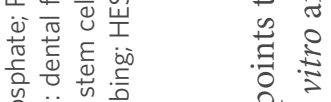

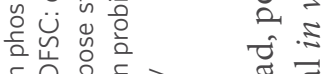

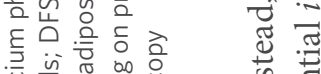

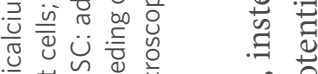

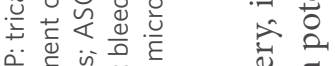

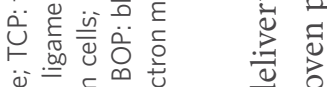

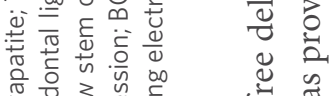

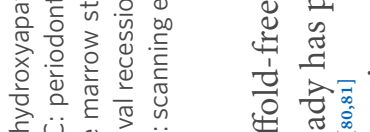

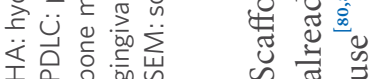

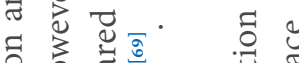

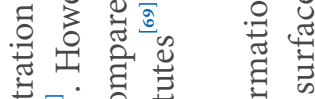

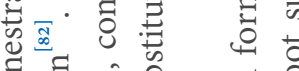

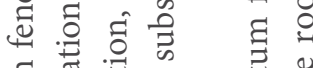

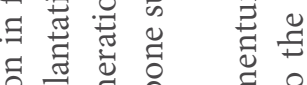

돌

矛芯芯志可

记苛

ठี $\sum_{0}^{\infty}$

चू है च

过苛专

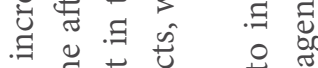

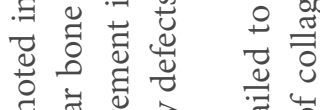

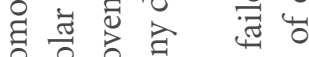

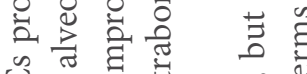

ब.

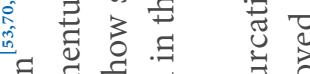

है द्यु

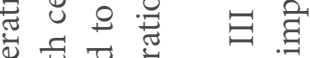

苛范苛 च

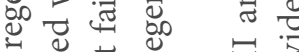

छ 䒕:

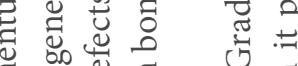

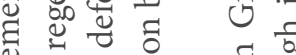

ठ

चै

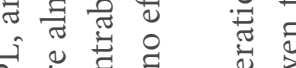

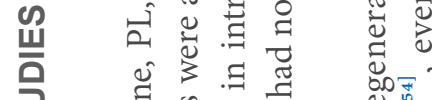

०ิ:

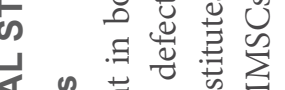

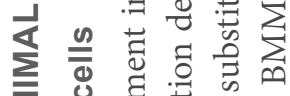

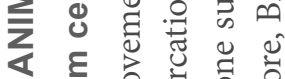

乙

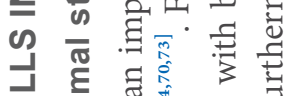

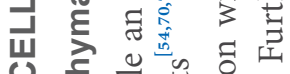

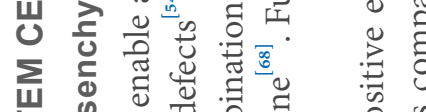

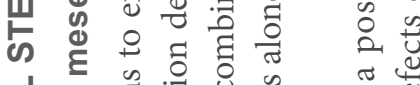

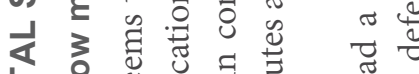

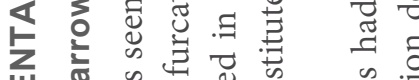

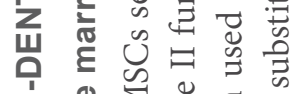

is

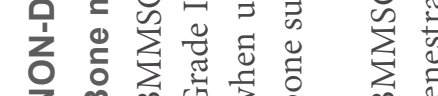

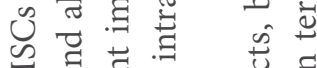

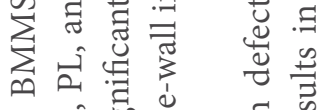


Grade III furcation, bone regeneration was not complete. When tested in intrabony defects, BMMSCs provided conflicting results for PL regeneration. One study reported that BMMSCs without bone substitutes did not promote an increased PL regeneration ${ }^{[82]}$. Another study reported that the combination of BMMSCs and bone substitutes provided significantly higher formation of new cementum and PL compared to bone substitutes alone ${ }^{[68]}$. A study which compared the performance of bone graft with PDLSCs or BMMSCs in intrabony defects reported less perpendicularly oriented newly inserted fibers in the BMMSCs group. Conflicting results were also reported in the use of BMMSCs that had undergone ex vivo osteogenic differentiation before use. Osteogenically differentiated BMMSCs (oBMMSCs) promoted increased bone formation but not cementum and PL regeneration.

\section{Adipose-derived stem cells}

ASCs and DPSCs appeared to have similar genetic expression patterns. ASCs transplanted in periodontal defects have been shown to favor cementum and PL fibers regeneration and to increase periodontal vascularization $^{[83,84]}$. Finally, ASCs in extraction sockets in a rabbit model showed potential for the regeneration of the alveolar bone structure ${ }^{[85]}$.

\section{DENTAL STEM CELLS IN ANIMAL STUDIES}

\section{Periodontal ligament stem cells}

As for PDLSCs, the majority of the studies showed the positive effect of the use of this type of cells for periodontal regeneration ${ }^{[86-91]}$, as reported in a recent systematic review of pre-clinical studies ${ }^{[92]}$. Importantly, PDLSCs have unique properties to form a cementum/PL complex-like structure when ectopically transplanted in animals ${ }^{[93,94]}$.

In fenestration defects (applied with hyaluronic acid sheet), they showed significantly greater formation of cementum, bone, and periodontal ligament than in control group ${ }^{[95]}$. When PDLSCs were associated with e-PTFE membranes on fenestration defects, it was observed that cementum formation was increased in the test group; however, no difference in bone formation was observed between test and control (e-PTFE membranes alone $)^{[96]}$. In fact, data on bone regeneration with PDLSCs are conflicting, even though their effect on cementum and PL is promising. Another study reported that PDLSCs improved bone formation in circumferential and fenestration defects, but not in three-wall defects treated without bone substitutes ${ }^{[0]}$. In intrabony defects, they provided improved periodontal regeneration with a nearly complete recovery of bone, cementum, and ligament when used in combination with beta tri-calcium phosphate ${ }^{[86,97]}$. The benefits were less pronounced but still maintained when used with non-supportive biomaterials ${ }^{[90,98]}$. PDLSCs' protocols without manipulation before direct implantation have been tested and proven effective, thus making the use of this cell type more sustainable ${ }^{[55]}$.

\section{Dental pulp stem cells}

DPSCs are another well studied lineage in the animal model. These cells were isolated almost 20 years ago $^{[35]}$ and found to be capable of forming lamellar bone after grafting ${ }^{[43,99]}$. Their use in different ways (injected, organized in sheet, and on different carriers) showed potential in regenerative procedure ${ }^{[67]}$. In the majority of the studies, the regeneration of all periodontal tissues was increased when DPSCs were used. Regenerated cementum was thicker in the group receiving bone substitutes plus DPSCs than in the control group treated with bone substitute alone, and it covered a larger surface of the root ${ }^{[67]}$, even though no noticeable difference in bone formation between the two groups was observed.

\section{Dental follicle precursor cells}

DFPCs may improve periodontal regeneration by PDLSCs in vivo. DFPCs appear to enhance the selfrenewal and multi-differentiation capacity of PDLSCs, which indicates that DFPCs could provide a beneficial microenvironment for periodontal regeneration by using PDLSCs ${ }^{[100]}$. 


\section{Stem cells from human exfoliated deciduous teeth}

When injected supra-periostally close to periodontal defects, SHEDs reduced gum bleeding, increased new attachment of $\mathrm{PL}$, and decreased osteoclast differentiation. Micro-CT analysis demonstrated increased bone volume and decreased distance of cementum-enamel junction to alveolar bone crest, compared to control with no treatment ${ }^{[46]}$. Histopathological photomicrographs showed newly regenerated bone and decreased number of inflammatory factors and osteoclasts. In a recent report, SHEDs were compared to PDLSCs for the treatment of intrabony defects. Both treatments were provided in combination with hydroxyapatite and beta tri-calcium phosphate scaffold. The results showed no significant difference between the two groups. SHEDs significantly improved periodontal regeneration compared to the scaffold alone, in a very similar way to PDLSCs ${ }^{[89]}$.

\section{Stem cells from apical papilla}

Local Injection of SCAPs increased CAL and bone volume in periodontal defects compared to injection of $0.9 \% \mathrm{NaCl}$. Histopathology results demonstrated remarkable regeneration in the SCAPs group, whereas regeneration of periodontal tissue was hardly found in the $0.9 \% \mathrm{NaCl}$ group ${ }^{[101]}$.

\section{Other cells}

Other stem cell types are less studied, yet have positive effects, especially $\mathrm{APCs}^{[102]}$, ASCs ${ }^{[103]}$, and GMSC $^{[104]}$. The two latter lineages have another positive characteristic: they can easily be retrieved in large quantity. As it is necessary to implant the highest possible number of cells to have better results, their disposability is definitely an advantage in comparison with other SC types. This advantage is also shared with iPSCs, which can be produced form a series of already differentiated cell types.

\section{HUMAN STUDIES}

\section{Case reports, case series, and retrospective studies}

Periodontal regeneration was investigated in human clinical studies using PDLSCs, DPSCs, and BMMSCs. DPSCs were observed in two case reports ${ }^{[105,106]}$ and three case series ${ }^{[107-109]}$. One of the case reports provided positive results for allogenic transplantation of DPSCs ${ }^{[106]}$. In parallel, some initial reports in humans demonstrated the clinical and radiographic efficacy of dental pulp micrografts in post-extraction alveolar defects $^{[110,111]}$. In general, it was found that, in periodontal regeneration, DPSC micrografts associated with surgical procedure were able to reduce PPD and increase CAL.

PDLSCs have been tested for regenerative procedures in intrabony defects and Grade II furcation defects ${ }^{[112]}$. A retrospective study, which included 16 defects in three patients, observed PPD reduction and CAL gain, thus supporting a potential benefit for the use of PDLSCs in periodontal regeneration ${ }^{[113]}$. Later on, in a case report ${ }^{[114]}$, it was observed that periodontal regenerative surgery using PDLSCs, incorporated in a gelatin sponge, produced PPD reduction, CAL gain, and radiographic bone fill. In Grade II furcation defects, PDLSCs provided good clinical results, reducing PPD and improving CAL in six months

BMMSCs have been tested in four case reports and one case series that reported good clinical outcomes for the periodontal regeneration of intrabony defects ${ }^{[115-118]}$ and Grade III furcation defects ${ }^{[119]}$.

\section{Randomized controlled trials}

Once the positive results in the use of stem cells in periodontal regeneration have been proven in animal and humans studies, RCTs are needed to assess the safety and the efficacy of the use of stem cells in periodontal regeneration compared to standard treatments.

Thus far, four RCTs ${ }^{[120-123]}$ have been published on assessing the efficacy of stem cells in periodontal regeneration, compared to open flap debridement ${ }^{[121,123]}$ or compared to the use of a scaffold alone without 
stem cells ${ }^{[120,122]}$ in intrabony defects. These RCTs differ in the type of stem cells selected (PDLSCs, DPSCs, or UC-MSCs) and in their application for the regenerative procedure (chairside use or isolation, differentiation, and cell culture in a laboratory). Shailini and coworkers ${ }^{[121]}$ applied the concept of "stem cell niche" to periodontal regeneration. In this prospective, randomized, single-blinded, controlled trial with parallel design, 16 patients with one intrabony defect were treated. In the test group, PDLSCs collected from an extracted tooth, together with the soft-tissue adherent to the extracted root surface and to the alveolar socket (PDL tissue niche), were directly mixed to a gelatin sponge and implanted in the intrabony defect. The control group was treated with an open flap debridement. The results after one year showed a greater improvement in PD reduction, CAL gain, and radiographic defect resolution in the group treated with PDLSCs; however, the differences were not statistically significant. No adverse effects were reported, thus suggesting the safety of the procedure.

Similar to Shailini, Chen and coworkers ${ }^{[120]}$ studied the efficacy of PDLSCs. PDLSCs harvested from an extracted tooth were isolated, characterized, and grown into sheets in a laboratory. In this single-center randomized trial, 41 intrabony defects were treated with either GTR and PDLSC sheets in combination with demineralized bovine bone matrix or with GTR and demineralized bovine bone matrix alone. The results after one year showed an increased alveolar bone height in both groups, without statistically significant differences between groups. As for the clinical periodontal parameters, no statistically significant differences were found for the increased CAL, PD, or GR between the cell and control groups. No adverse effects in the use of PDL cells sheets were reported.

While Chen and Shailini evaluated the efficacy of PDLSCs, Ferrarotti and coworkers ${ }^{[122]}$ evaluated the use of micrografts containing DPSCs delivered into intrabony defects in a collagen scaffold. In this parallel, double-blind, prospective randomized trial, 29 patients with an intrabony defect were treated with either minimally invasive surgical technique (MIST) plus dental pulp micrografts in a collagen sponge biocomplex (test) or MIST plus collagen sponge alone (control). The micrografts enriched in DPSCs were obtained from the pulp chamber of an extracted tooth, dissociated by the use of a biological tissue disaggregator (Rigenera Machine System, Rigenera; HBW, Turin, Italy), and then seeded on a collagen sponge scaffold. After one year, the results showed a statistically significant greater PD reduction, CAL gain, and radiographic bone defect fill in the group treated with DPSCs on a scaffold, compared to the scaffold alone. No adverse effects were reported.

Instead of using dental stem cells, Dhote and coworkers ${ }^{[123]}$ tested the efficacy of non-dental stem cells on periodontal regeneration, focusing their attention on the umbilical cord MSCs (UC-MSCs). In this parallel designed RCT, 24 periodontal intrabony defects in 14 patients were treated by either applying allogeneic cord blood MSCs on a beta-tricalcium phosphate (beta-TCP) scaffold in combination with platelet-derived growth factor-BB (rh-PDGF-BB) or by open flap debridement (OFD). The results after six months showed significantly greater CAL gain, PPD reduction and radiographic defect fill in the group treated with a combination of allogeneic UC-MSCs, rh-PDGF-BB, and beta-TCP scaffold compared to the OFD. No adverse effects were reported demonstrating the safety of mesenchymal stem cells derived from umbilical cord for dental tissue engineering.

An interesting field of application for stem cells is represented by defects that cannot be predictably treated with the techniques available today, such as furcation defects or supracrestal regeneration. The application of stem cells to enhance the regeneration of furcations was tested in an RCT by Akbay and coworkers ${ }^{[113]}$, which evaluated the periodontal regenerative potential of PL grafts in Grade II furcation defects. Ten patients were treated in a split mouth design: on one side, a molar was treated with a coronally positioned flap with autogenous PDLSCs grafts obtained from third molars, while, on the other side, with a coronally positioned flap alone. PL remnants attached to cementum and cellular cementum were collected by 
scaling the surface of the extracted third molars with sterile curettes and grafted directly into the furcation defect. After six months, a reentry was performed on both sides to assess the defect fill. In one randomly selected patient, gingival biopsies were taken on test and control sites. The results after six months showed improvement in terms of horizontal and vertical defect fill, PD, and CAL in both groups, with significantly better results in PD reduction for the grafted sites. No adverse effects or foreign body reactions were observed in PDL grafts.

In general, the RCTs published thus far suggest safety in the use of stem cells and promising clinical results [Table 3]. The need of a tooth that has to be extracted in order to harvest PDLSCs or DPSCs is a drawback of these cell therapies. This may be considered the main issue in the use of stem cells. Harvest, isolation, and possible differentiation of stem cells are time-consuming, complex, and expensive processes. Protocols with direct use of the harvested cells were proposed and evaluated by Shailini and Ferrarotti ${ }^{[121,122]}$; the former suggested grafting directly the PDL tissues in the defect, while the latter suggested using biological tissue disaggregation to obtain a micrograft. The advantage of these protocols is the reduction of time and costs of treatment; however, the presence and viability of the cells implanted in the defects cannot be proven since no isolation and characterization are performed.

The results of the RCTs available in the literature show promising indirect measurements of the effectiveness of the regeneration process, assessed by means of clinical and radiographic parameters. However, true regeneration can only be proven by histological analysis, impossible to carry out in any of the studies because of ethical limitations.

\section{FUTURE PERSPECTIVES FOR STEM CELLS IN PERIODONTAL REGENERATION}

To overcome some limitation of the present cell therapy and based on the promising results of this animal and human research of stem cells, a further step forward has been proposed by researchers: exogenous human MSCs.

Thus far, autologous use of stem cells has been applied only, using an extracted tooth as the source for either PDLSCs or DPSCs. To overcome this limitation, as well as the limitation of the use of stem cells in elderly people, whose regenerative capacity is limited, the use of exogenous or allogenic stem cells has been proposed $^{[124]}$.

Exogenous human MSCs have already been tested in cases of biologic refractory luminal Crohn's disease with fistulae formation, cranial defects, myocardial regeneration, and patients with aging frailty. Exogenous MSC infusion seemed to be very well tolerated, with only light and short-term effects and frequently no adverse reaction at all. Thus, exogenous MSCs appear to be a feasible technique for periodontal and regenerative treatments in general.

Pluripotent stem cells generated from somatic cells (iPSCs) are a possible stem cell lineage to study for periodontal regeneration ${ }^{[125]}$. They have the potential to differentiate in a spectrum of different cells and tissues. In dental research, iPSCs-derived mesenchymal cells and osseoprogenitor cells were investigated by scientists with great interest. To be used, these cells need to go through a process of transdifferentiation. In this process, mature somatic cells undergo a transformation to a different somatic cell without going through a pluripotent state or a progenitor phase. This process is also called lineage switching or linage conversion. By means of this process, epigenetic modifications, by directly reprogramming non-osteoblasts cells into functional osteoblasts, have started to be considered as a new therapeutic approach for alveolar bone regeneration. At present, more knowledge for applying these cells to cell-based therapy is needed and preclinical and clinical research will enhance our understanding of these processes. iPSCs reprogrammed from non-dental cells have shown promising results in periodontal regeneration in mice, in combination 


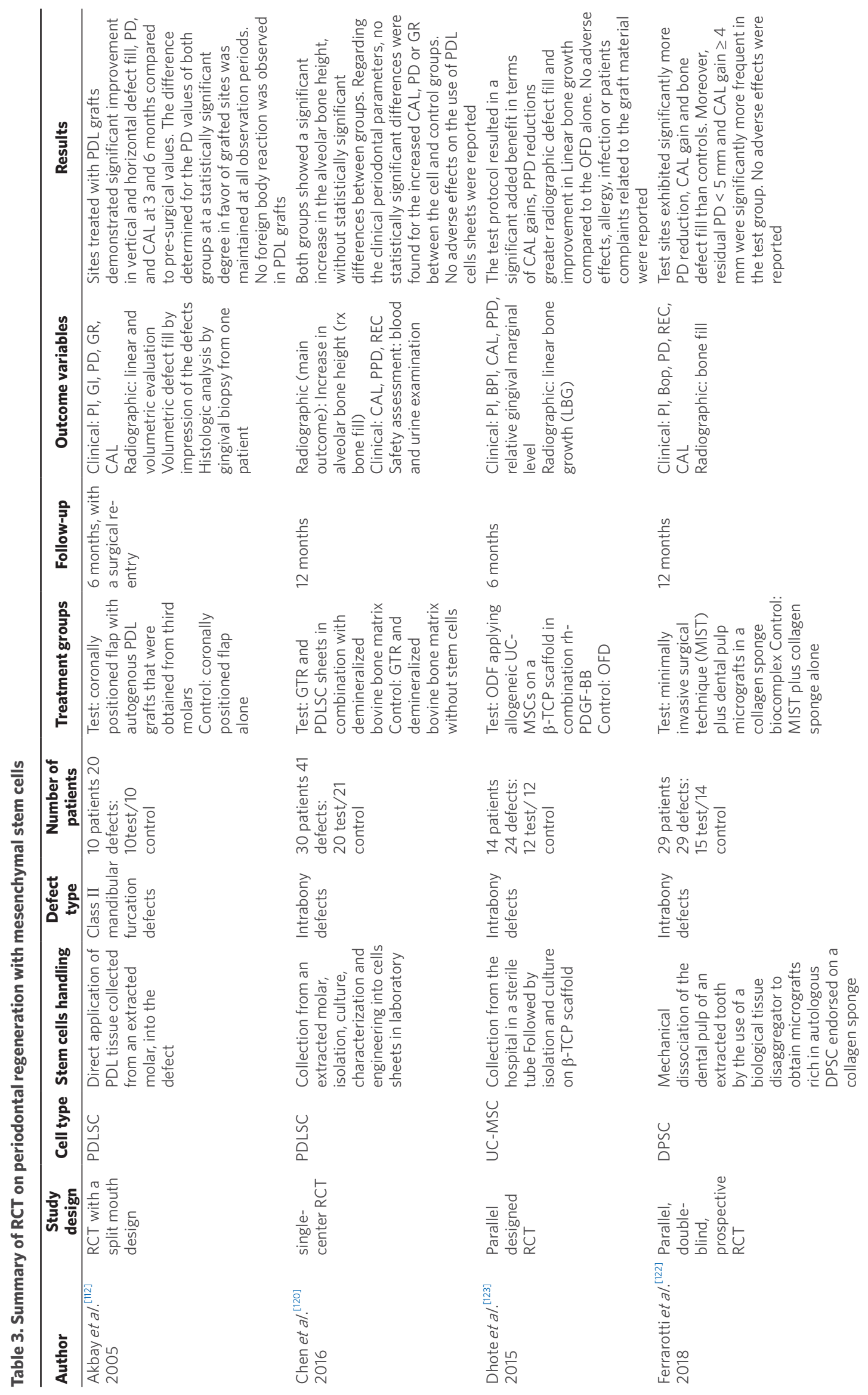




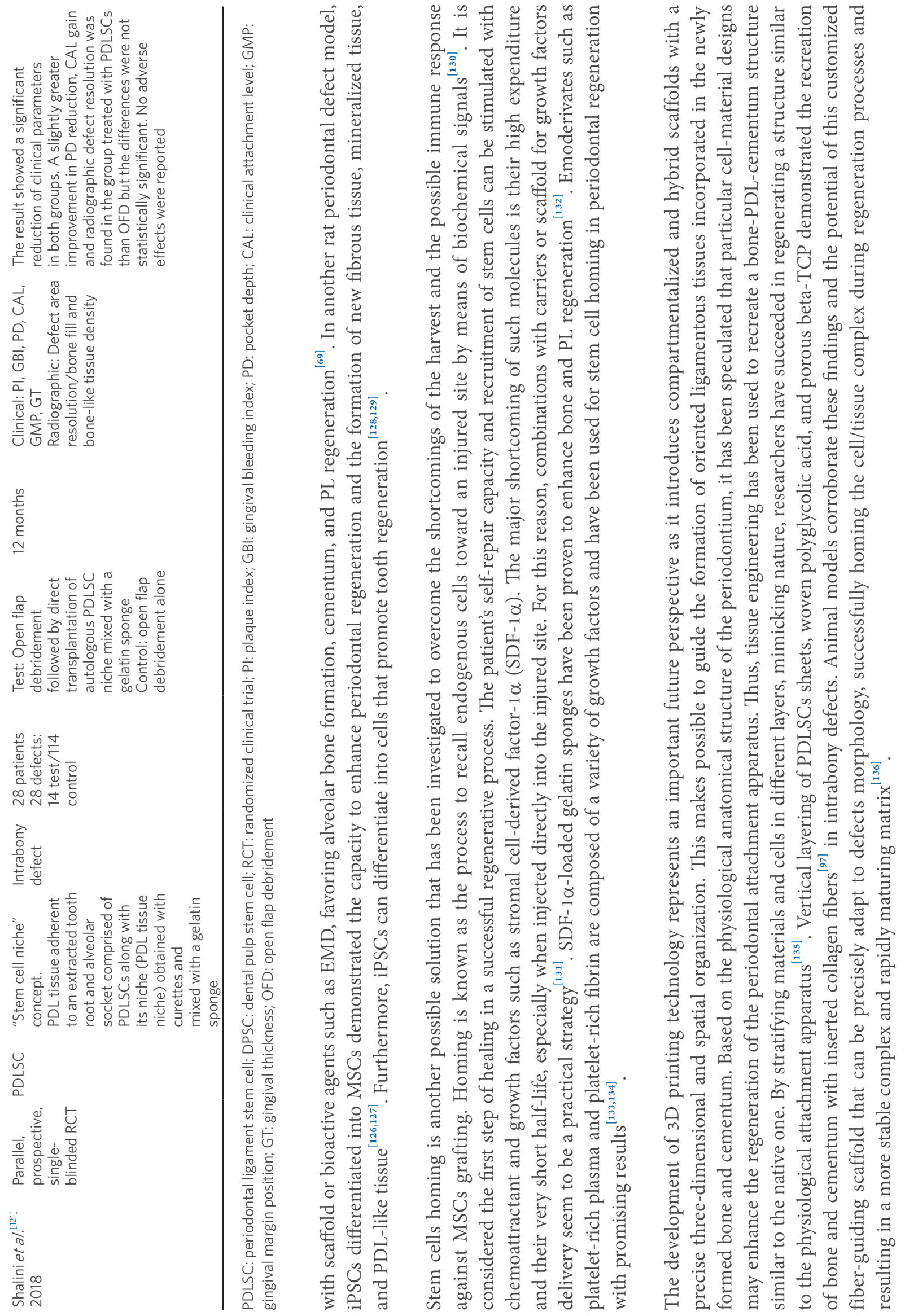


With all these different possible therapeutic approaches, we must not forget the four key factors needed to reach the goal of a "restitutio ad integrum" of the periodontal apparatus and have a true regeneration: cells, environment, signals, and time. Stem cells (MSCs, PDLSCs, iPSCs, etc.) have to be put or recruited in a favorable and protected environment (e.g., 3D scaffold) and guided in their transformation process by signaling molecules (homing and differentiating factors), for long enough to mature.

A pivotal role is also played by MSCs adhesion capacities and longevity. In fact, cell adhesion is critical for survival, proliferation, and differentiation of MSCs. Similarly, MSCs' longevity may influence the outcomes of the regeneration therapies. Therefore, to maximize the potential of tissue engineering therapies, researchers have to focus their attention on well-designed scaffolds and precise signaling molecules. The former are meant to favor adhesion and impede anoikis and the latter are to be used both before and during transplantation to stimulate cell proliferation and longevity in order to overcome possible low cells survival rates ${ }^{[137]}$.

These different methods might have to be combined to achieve the maximum result in tissue regeneration. Ideally, an optimum protocol should focus on three key points: (1) the use exogenous or endogenous MSCs pre-treated with bioactive factors; (2) a protective scaffold that favors cells adhesion and spreading; and (3) signaling molecule doping of the scaffold to boost cells' regenerative abilities, increase their longevity, and recruit nearby already present stem cells.

Finally, the future research is focused on the possible application of cell therapy for regeneration. The fields that are being investigated extend from what is possible at the present time (dentin-pulp regeneration and periodontal regeneration) to future applications (whole-tooth regeneration) ${ }^{[138]}$. Thus far, the evidence for whole-tooth regeneration is limited in vitro and in animal models, but research is progressing quickly.

\section{CONCLUSION}

The goal of periodontal tissue engineering is to restore the normal function of the diseased periodontium to support the teeth. To achieve this objective, stem cells, appropriate scaffold, and infection control are required at the diseased site. Even if some studies reported conflicting results and irregular outcomes, the available evidence in animal models supports the applicability of stem cells in periodontal tissue regeneration. We hypothesize that this heterogeneity of results could be due to the different methodologies used. In fact, differences in study models (animal and defect ones), treatment modalities, isolation protocols, and study designs are some of the factors that can influence the final results of the investigation. This leads to the present impossibility to propose a specific protocol or MSC type which may be considered superior to others. The efficacy and safety of cell-based interventions in humans have been proven by case reports and case series, but sparsely by RCTs. PDLSCs and DPSCs have been tested and showed promising results both in animal models and in humans. However, it is yet to be defined which protocol performs better, and, although experimental data have allowed the beginning of clinical trials in periodontal cell therapy, proper consideration of the cell source, material type, and regulatory concerns is crucial to facilitate clinical translation. Furthermore, histological evidence of periodontal regeneration is still lacking and the power of studies is hampered by major limitations. One of the major shortcomings is the defects used in animal models, which may not adequately reflect the complex microbiological and immuneinflammatory environment of the periodontal pocket. Actually, in many cases, the periodontal defects generated in the currently used animal studies do not sufficiently represent those of human periodontitis. Evidence for exogenous MSCs grafting, 3D printed-scaffold, and stem cell homing is promising but still limited. Despite all these shortcomings, tissue engineering in periodontology is fascinating and hopefully will help clinicians to overcome the limitations of present periodontal treatments. In fact, MSCs have provided surprisingly favorable outcomes in conditions in which standard procedures for periodontal 
regeneration are unsatisfactory, for instance in furcation defects. In this field, the development of cell-based therapy could provide its greatest benefit in the future.

\section{DECLARATIONS}

\section{Authors' contributions}

Performed data acquisition, as well as provided administrative, technical, and material support: Citterio F, Gualini G, Fierravanti L

Supervision: Aimetti M

Write the final review and tables: Citterio F, Gualini G, Fierravanti L

\section{Availability of data and materials}

Not applicable.

\section{Financial support and sponsorship}

None.

\section{Conflicts of interest}

All authors declared that there are no conflicts of interest.

\section{Ethical approval and consent to participate}

Not applicable.

\section{Consent for publication}

Not applicable.

\section{Copyright}

(c) The Author(s) 2020.

\section{REFERENCES}

1. Aimetti M, Perotto S, Castiglione A, Mariani GM, Ferrarotti F, et al. Prevalence of periodontitis in an adult population from an urban area in North Italy: findings from a cross-sectional population-based epidemiological survey. J Clin Periodontol 2015;42:622-31.

2. Chapple I. Iain Chapple: 'as a Clinician, You Assume That People Know What Periodontitis Is'. Vol 215. Br Dent J 2013:431-4.

3. Ide M, Linden GJ. Periodontitis, cardiovascular disease and pregnancy outcome--focal infection revisited? Br Dent J 2014;217:467-74.

4. Lalla E, Papapanou PN. Diabetes mellitus and periodontitis: a tale of two common interrelated diseases. Nat Rev Endocrinol 2011;7:738-48.

5. Araújo VMA, Melo IM, Lima V. Relationship between periodontitis and rheumatoid arthritis: review of the literature. Mediators Inflamm 2015;2015:259074.

6. Loos BG. Systemic effects of periodontitis. Int J Dent Hyg 2006;4:34-52.

7. Chapple ILC. Time to take periodontitis seriously. BMJ 2014;348:g2645.

8. Chapple IL, Van der Weijden F, Doerfer C, Herrera D, Shapira L, et al. Primary prevention of periodontitis: managing gingivitis. J Clin Periodontol 2015;42:S71-6.

9. Petersen PE, Ogawa H. The global burden of periodontal disease: towards integration with chronic disease prevention and control. Periodontol 2000 2012;60:15-39.

10. Pihlstrom BL, Michalowicz BS, Johnson NW. Periodontal diseases. Lancet 2005;366:1809-20.

11. Cortellini P, Buti J, Pini Prato G, Tonetti MS. Periodontal regeneration compared with access flap surgery in human intra-bony defects 20year follow-up of a randomized clinical trial: tooth retention, periodontitis recurrence and costs. J Clin Periodontol 2017;44:58-66.

12. Suvan J, Leira Y, Moreno F, Graziani F, Derks J, et al. Subgingival instrumentation for treatment of periodontitis. a systematic review. J Clin Periodontol 2019; doi: 10.1111/jcpe.13245.

13. Sanz-Sánchez I, Montero E, Citterio F, Romano F, Molina A, et al. Efficacy of access flap procedures compared to subgingival debridement in the treatment of periodontitis. A systematic review and meta-analysis. J Clin Periodontol 2020; doi: 10.1111/jcpe.13259.

14. Trombelli L, FrancESCshetti G, Farina R. Effect of professional mechanical plaque removal performed on a long-term, routine basis in the secondary prevention of periodontitis: a systematic review. J Clin Periodontol 2015;42:S221-36.

15. Matuliene G, Pjetursson BE, Salvi GE, Schmidlin K, Brägger U, et al. Influence of residual pockets on progression of periodontitis and tooth loss: results after 11 years of maintenance. J Clin Periodontol 2008;35:685-95. 
16. Claffey N, Egelberg J. Clinical indicators of probing attachment loss following initial periodontal treatment in advanced periodontitis patients. J Clin Periodontol 1995;22:690-6.

17. Graziani F, Gennai S, Cei S, Cairo F, Baggiani A, et al. Clinical performance of access flap surgery in the treatment of the intrabony defect. A systematic review and meta-analysis of randomized clinical trials. J Clin Periodontol 2012;39:145-56.

18. Aimetti M, Mariani GM, Ferrarotti F, Ercoli E, Audagna M, et al. Osseous resective surgery with and without fibre retention technique in the treatment of shallow intrabony defects: a split-mouth randomized clinical trial. J Clin Periodontol 2015;42:182-9.

19. Ferrarotti F, Giraudi M, Citterio F, Fratini A, Gualini G, et al. Pocket elimination after osseous resective surgery: a systematic review and meta-analysis. J Clin Periodontol 2020; doi: 10.1111/jcpe.13281.

20. Cortellini P, Tonetti MS. Clinical performance of a regenerative strategy for intrabony defects: scientific evidence and clinical experience. J Periodontol 2005;76:341-50.

21. Kao RT, Nares S, Reynolds MA. Periodontal regeneration - intrabony defects: a systematic review from the AAP Regeneration Workshop. J Periodontol 2015;86:S77-104.

22. Avila-Ortiz G, De Buitrago JG, Reddy MS. Periodontal regeneration - furcation defects: a systematic review from the AAP Regeneration Workshop. J Periodontol 2015;86:S108-30.

23. Cortellini P, Tonetti MS. Clinical concepts for regenerative therapy in intrabony defects. Periodontol 2000 2015;68:282-307.

24. Gottlow J, Nyman S, Karring T, Lindhe J. New attachment formation as the result of controlled tissue regeneration. J Clin Periodontol 1984;11:494-503.

25. Cortellini P, Tonetti MS. A minimally invasive surgical technique with an enamel matrix derivative in the regenerative treatment of intrabony defects: a novel approach to limit morbidity. J Clin Periodontol 2007;34:87-93.

26. Cortellini P, Tonetti MS. Improved wound stability with a modified minimally invasive surgical technique in the regenerative treatment of isolated interdental intrabony defects. J Clin Periodontol 2009;36:157-63.

27. Harrel SK. A minimally invasive surgical approach for periodontal regeneration: surgical technique and observations. J Periodontol 1999;70:1547-57.

28. Trombelli L, Farina R, FrancESCshetti G, Calura G. Single-flap approach with buccal access in periodontal reconstructive procedures. J Periodontol 2009;80:353-60.

29. Hammarström L. The role of enamel matrix proteins in the development of cementum and periodontal tissues. Ciba Found Symp 1997;205:246-60.

30. Trombelli L, Farina R. Clinical outcomes with bioactive agents alone or in combination with grafting or guided tissue regeneration. J Clin Periodontol 2008;35:117-35.

31. Palmer RM, Cortellini P. Group B of European Workshop on Periodontology. Periodontal tissue engineering and regeneration: Consensus Report of the Sixth European Workshop on Periodontology. J Clin Periodontol 2008;35:83-6.

32. Biehl JK, Russell B. Introduction to stem cell therapy. J CardiovASCs Nurs 2009;24:98-105.

33. Kobolak J, Dinnyes A, Memic A, Khademhosseini A, Mobasheri A. Mesenchymal stem cells: identification, phenotypic characterization, biological properties and potential for regenerative medicine through biomaterial micro-engineering of their niche. Methods 2016;99:62-8.

34. Huang GT, Gronthos S, Shi S. Mesenchymal stem cells derived from dental tissues vs. those from other sources: their biology and role in regenerative medicine. J Dent Res 2009;88:792-806.

35. Gronthos S, Mankani M, Brahim J, Robey PG, Shi S. Postnatal human dental pulp stem cells (DPSCs) in vitro and in vivo. Proc Natl Acad Sci U S A 2000;97:13625-30.

36. Miura M, Gronthos S, Zhao M, Lu B, Fisher LW, et al. SHEDs: stem cells from human exfoliated deciduous teeth. Proc Natl Acad Sci U S A 2003;100:5807-12.

37. Seo BM, Miura M, Gronthos S, Bartold PM, Batouli S, et al. Investigation of multipotent postnatal stem cells from human periodontal ligament. Lancet 2004;364:149-55.

38. Morsczeck C, Moehl C, Götz W, Heredia A, Schäffer TE, et al. In vitro differentiation of human dental follicle cells with dexamethasone and insulin. Cell Biol Int 2005;29:567-75.

39. Sonoyama W, Liu Y, Yamaza T, Tuan RS, Wang S, et al. Characterization of the apical papilla and its residing stem cells from human immature permanent teeth: a pilot study. J Endod 2008;34:166-71.

40. Gronthos S, Brahim J, Li W, Fisher LW, Cherman N, et al. Stem cell properties of human dental pulp stem cells. J Dent Res 2002;81:531-5.

41. Tziafas D, Kodonas K. Differentiation potential of dental papilla, dental pulp, and apical papilla progenitor cells. J Endod 2010;36:781-9.

42. Yu J, He H, Tang C, Zhang G, Li Y, et al. Differentiation potential of STRO-1+ dental pulp stem cells changes during cell passaging. BMC Cell Biol 2010;11:32.

43. Graziano A, d'Aquino R, Cusella-De Angelis MG, Francesco FD, Giordano A, et al. Scaffold's surface geometry significantly affects human stem cell bone tissue engineering. J Cell Physiol 2008;214:166-72.

44. Papaccio G, Graziano A, d'Aquino R, Graziano MF, Pirozzi G, et al. Long-term cryopreservation of dental pulp stem cells (SBP-DPSCs) and their differentiated osteoblasts: a cell source for tissue repair. J Cell Physiol 2006;208:319-25.

45. Su WT, Chiou WL, Yu HH, Huang TY. Differentiation potential of SHEDs using biomimetic periosteum containing dexamethasone. Mater Sci Eng C Mater Biol Appl 2016;58:1036-45.

46. Gao X, Shen Z, Guan M, Huang Q, Chen L, et al. Immunomodulatory role of stem cells from human exfoliated deciduous teeth on periodontal regeneration. Tissue Eng Part A 2018;24:1341-53.

47. Nakamura S, Yamada Y, Katagiri W, Sugito T, Ito K, et al. Stem cell proliferation pathways comparison between human exfoliated deciduous teeth and dental pulp stem cells by gene expression profile from promising dental pulp. J Endod 2009;35:1536-42. 
48. Liu L, Michowski W, Kolodziejczyk A, Sicinski P. The cell cycle in stem cell proliferation, pluripotency and differentiation. Nat Cell Biol 2019;21:1060-7.

49. Chrepa V, Pitcher B, Henry MA, Diogenes A. Survival of the Apical papilla and its resident stem cells in a case of advanced pulpal necrosis and apical periodontitis. J Endod 2017;43:561-7.

50. Nada OA, El Backly RM. stem cells from the apical papilla (SCAPs) as a tool for endogenous tissue regeneration. Front Bioeng Biotechno 2018;6:103.

51. Hu B, Nadiri A, Kuchler-Bopp S, Perrin-Schmitt F, Peters H, et al. Tissue engineering of tooth crown, root, and periodontium. Tissue Eng 2006;12:2069-75.

52. Hu B, Unda F, Bopp-Kuchler S, Jimenez L, Wang XJ, et al. Bone marrow cells can give rise to ameloblast-like cells. J Dent Res 2006;85:416-21.

53. Hasegawa N, Kawaguchi H, Hirachi A, Takeda K, Mizuno N, et al. Behavior of transplanted bone marrow-derived mesenchymal stem cells in periodontal defects. J Periodontol 2006;77:1003-7.

54. Yang Y, Rossi FM, Putnins EE. Periodontal regeneration using engineered bone marrow mesenchymal stromal cells. Biomaterials 2010;31:8574-82.

55. Ohazama A, Modino SA, Miletich I, Sharpe PT. Stem-cell-based tissue engineering of murine teeth. J Dent Res 2004;83:518-22.

56. Evans MJ, Kaufman MH. Establishment in culture of pluripotential cells from mouse embryos. Nature 1981;292:154-6.

57. Inanç B, Elçin AE, Elçin YM. In vitro differentiation and attachment of human embryonic stem cells on periodontal tooth root surfaces. Tissue Eng Part A 2009;15:3427-35.

58. Ning F, Guo Y, Tang J, Zhou J, Zhang H, et al. Differentiation of mouse embryonic stem cells into dental epithelial-like cells induced by ameloblasts serum-free conditioned medium. Biochem Biophys Res Commun 2010;394:342-7.

59. Takahashi K, Yamanaka S. Induction of pluripotent stem cells from mouse embryonic and adult fibroblast cultures by defined factors. Cell 2006;126:663-76.

60. Wada N, Wang B, Lin NH, Laslett AL, Gronthos S, et al. Induced pluripotent stem cell lines derived from human gingival fibroblasts and periodontal ligament fibroblasts. J Periodontal Res 2011;46:438-47.

61. Yan X, Qin H, Qu C, Tuan RS, Shi S, et al. iPS cells reprogrammed from human mesenchymal-like stem/progenitor cells of dental tissue origin. Stem Cells Dev 2010;19:469-80.

62. Xu XY, Li X, Wang J, He XT, Sun H-H, et al. Concise review: periodontal tissue regeneration using stem cells: strategies and translational considerations. Stem Cells Transl Med 2019;8:392-403.

63. Portron S, Soueidan A, Marsden AC, Rakic M, VernerC, et al. Periodontal regenerative medicine using mesenchymal stem cells and biomaterials: a systematic review of pre-clinical studies. Dent Mater J 2019;38:867-83.

64. Shamsul BS, Aminuddin BS, Ng MH, Ruszymah BH. Age and gender effect on the growth of bone marrow stromal cells in vitro. Med J Malaysia 2004;59:196-7.

65. Balduino A, Mello-Coelho V, Wang Z, Taichman RS, Krebsbach PH, et al. Molecular signature and in vivo behavior of bone marrow endosteal and subendosteal stromal cell populations and their relevance to hematopoiesis. Exp Cell Res 2012;318:2427-37.

66. Suaid FF, Ribeiro FV, Gomes TR, Silvério KG, Carvalho MD, et al. Autologous periodontal ligament cells in the treatment of class III furcation defects: a study in dogs. J Clin Periodontol 2012;39:377-84.

67. Khorsand A, Eslaminejad MB, Arabsolghar M, Paknejad M, Ghaedi B, et al. Autologous dental pulp stem cells in regeneration of defect created in canine periodontal tissue. J Oral Implantol 2013;39:433-43.

68. Paknejad M, Eslaminejad MB, Ghaedi B, Rokn AR, Khorsand A, et al. Isolation and assessment of mesenchymal stem cells derived from bone marrow: histologic and histomorphometric study in a canine periodontal defect. J Oral Implantol 2015;41:284-91.

69. Duan X, Tu Q, Zhang J, Ye J, C Sommer, et al. Application of induced pluripotent stem (iPS) cells in periodontal tissue regeneration. J Cell Physiol 2011;226:150-7.

70. Simsek SB, Keles GC, Baris S, Cetinkaya BO. Comparison of mesenchymal stem cells and autogenous cortical bone graft in the treatment of class II furcation defects in dogs. Clin Oral Investig 2012;16:251-8.

71. Bakopoulou A, Apatzidou D, Aggelidou E, Gousopoulou E, Leyhausen G, et al. Isolation and prolonged expansion of oral mesenchymal stem cells under clinical-grade, GMP-compliant conditions differentially affects "stemness" properties. Stem Cell Res Ther 2017;8:247.

72. Kawaguchi H, Hirachi A, Hasegawa N, Iwata T, Hamaguchi H, et al. Enhancementum of periodontal tissue regeneration by transplantation of bone marrow mesenchymal stem cells. J Periodontol 2004;75:1281-7.

73. Nagahara T, Yoshimatsu S, Shiba H, Kawaguchi H, Takeda K, et al. Introduction of a mixture of $\beta$-tricalcium phosphate into a complex of bone marrow mesenchymal stem cells and type I collagen can augment the volume of alveolar bone without impairing cementum regeneration. J Periodontol 2015;86:456-64.

74. Zang S, Jin L, Kang S, Hu X, Wang M, et al. Periodontal wound healing by transplantation of jaw bone marrow-derived mesenchymal stem cells in chitosan/anorganic bovine bone carrier into one-wall infrabony defects in beagles. J Periodontol 2016;87:971-81.

75. Fujioka-Kobayashi M, Müller HD, Mueller A, Lussi A, Sculean A, et al. In vitro effects of hyaluronic acid on human periodontal ligament cells. BMC Oral Health 2017;17:44.

76. Takeda K, Sakai N, Shiba H, Fujita T, Kajiya M, et al. Characteristics of high-molecular-weight hyaluronic acid as a brain-derived neurotrophic factor scaffold in periodontal tissue regeneration. Tissue Eng Part A 2011;17:955-67.

77. Zhang J, Chen Y, Xu J, Wang J, Li C, et al. Tissue engineering using 3D printed nano-bioactive glass loaded with NELL1 gene for repairing alveolar bone defects. Regen Biomater 2018;5:213-20.

78. Funda G, TASCshieri S, Bruno GA, Grecchi E, Paolo S, et al. Nanotechnology scaffolds for alveolar bone regeneration. Materials (Basel) 
2020;13:201.

79. Baba S, Yamada Y, Komuro A, Yotsui Y, Umeda M, et al. Phase I/II trial of autologous bone marrow stem cell transplantation with a three-dimensional woven-fabric scaffold for periodontitis. Stem Cells Int 2016;2016:6205910.

80. Motoike S, Kajiya M, Komatsu N, Horikoshi S, Ogawa T, et al. Clumps of mesenchymal stem cell/extracellular matrix complexes generated with xeno-free conditions facilitate bone regeneration via direct and indirect osteogenesis. Int J Mol Sci 2019;20:3970.

81. Takewaki M, Kajiya M, Takeda K, Horikoshi S, Ogawa T, et al. MSCs/ECM cellular complexes induce periodontal tissue regeneration. J Dent Res 2017;96:984-91.

82. Cai X, Yang F, Yan X, Yang W, Yu N, et al. Influence of bone marrow-derived mesenchymal stem cells pre-implantation differentiation approach on periodontal regeneration in vivo. J Clin Periodontol 2015;42:380-9.

83. Lemaitre M, Monsarrat P, BlASCso-Baque V, Loubières P, Burcelin R, et al. Periodontal tissue regeneration using syngeneic adiposederived stromal cells in a mouse model. Stem Cells Transl Med 2017;6:656-65.

84. Tobita M, Uysal AC, Ogawa R, Hyakusoku H, Mizuno H. Periodontal tissue regeneration with adipose-derived stem cells. Tissue Eng Part A 2008;14:945-53.

85. Hung CN, Mar K, Chang HC, Chiang YL, Hu HY, et al. A comparison between adipose tissue and dental pulp as sources of MSCs for tooth regeneration. Biomaterial 2011;32:6995-7005.

86. Ding G, Liu Y, Wang W, Wei F, Liu D, et al. Allogeneic periodontal ligament stem cell therapy for periodontitis in swine. Stem Cells 2010;28:1829-38

87. Fu X, Jin L, Ma P, Fan Z, Wang S. Allogeneic stem cells from deciduous teeth in treatment for periodontitis in miniature swine. J Periodontol 2014;85:845-51.

88. Tsumanuma Y, Iwata T, Kinoshita A, Washio K, Yoshida T, et al. Allogeneic transplantation of periodontal ligament-derived multipotent mesenchymal stromal cell sheets in canine critical-size supra-alveolar periodontal defect model. Biores Open Access 2016;5:22-36.

89. Zhu B, Liu W, Zhang H, Zhao X, Duan Y, et al. Tissue-specific composite cell aggregates drive periodontium tissue regeneration by reconstructing a regenerative microenvironment. J Tissue Eng Regen Med 2017;11:1792-805.

90. Nuñez J, Sanz-BlASCso S, Vignoletti F, Muñoz F, Arzate H, et al. Periodontal regeneration following implantation of cementum and periodontal ligament-derived cells. J Periodontal Res 2012;4:33-44.

91. Gao ZH, Hu L, Liu GL, Wei FL, Liu Y, et al. Bio-root and implant-based restoration as a tooth replacementum alternative. J Dent Res 2016;95:642-9.

92. Tassi SA, Sergio NZ, Misawa MYO, Villar CC. Efficacy of stem cells on periodontal regeneration: systematic review of pre-clinical studies. J Periodont Res 2017;52:793-812.

93. Seo BM, Miura M, Gronthos S, Zhang X, Zhu SX, et al. Investigation of multipotent postnatal stem cells from human periodontal ligament. Lancet 2004;364:149-55.

94. Gronthos S, Mrozik K, Shi S, Bartold PM. Ovine periodontal ligament stem cells: isolation, characterization, and differentiation potential. Calcif Tissue Int 2006;79:310-7.

95. Akizuki T, Oda S, Komaki M, Tsuchioka H, Kawakatsu N, et al. Application of periodontal ligament cell sheet for periodontal regeneration: a pilot study in beagle dogs. J Periodontal Res 2005;40:245-51.

96. Nakahara T, Nakamura T, Kobayashi E, Kuremoto KI, Matsuno T, et al. In situ tissue engineering of periodontal tissues by seeding with periodontal ligament-derived cells. Tissue Eng 2004;10:537-44.

97. Iwata T, Yamato M, Tsuchioka H, Takagi R, Mukobata S, et al. Periodontal regeneration with multi-layered periodontal ligament-derived cell sheets in a canine model. Biomaterials 2009;30:2716-23.

98. Inukai T, Katagiri W, Yoshimi R, Osugi M, Kawai T, et al. Novel application of stem cell-derived factors for periodontal regeneration. Biochem Biophys Res Commun 2013;430:763-8.

99. d'Aquino R, Graziano A, Sampaolesi M, Laino G, Pirozzi G, et al. Human postnatal dental pulp cells co-differentiate into osteoblasts and endotheliocytes: a pivotal synergy leading to adult bone tissue formation. Cell Death Differ 2007;14:1162-71.

100. Liu J, Ruan J, Weir MD, Ren K, Schneider A, et al. Periodontal bone-ligament-cementum regeneration via scaffolds and stem cells. Cells 2019;8:537.

101. Li G, Han N, Zhang X, Yang H, Cao Y, et al. Local injection of allogeneic stem cells from apical papilla enhanced periodontal tissue regeneration in minipig model of periodontitis. Biomed Res Int 2018;2018:3960798.

102. Yamamiya K, Okuda K, Kawase T, Hata K, Wolff LF, et al. Tissue-engineered cultured periosteum used with platelet-rich plasma and hydroxyapatite in treating human osseous defects. J Periodontol 2008;79:811-8.

103. Tobita M, Mizuno H. Adipose-derived stem cells and periodontal tissue engineering. Int J Oral Maxillofac Implants 2013;28:e487-93.

104. Fawzy El-Sayed KM, Paris S, Becker S, Kassem N, Ungefroren H, et al. Isolation and characterization of multipotent postnatal stem/ progenitor cells from human alveolar bone proper. J Craniomaxillofac Surg 2012;40:735-42.

105. Aimetti M, Ferrarotti F, Cricenti L, Mariani GM, Romano F. Autologous dental pulp stem cells in periodontal regeneration: a case report. Int J Periodontics Restorative Dent 2014;34:s27-33.

106. Hernández-Monjaraz B, Santiago-Osorio E, Ledesma-Martínez E, Alcauter-Zavala A, Mendoza-Núñez VM. Retrieval of a periodontally compromised tooth by allogeneic grafting of mesenchymal stem cells from dental pulp: a case report. J Int Med Res 2018;46:2983-93.

107. Aimetti M, Ferrarotti F, Mariani GM, Cricenti L, Romano F. Use of dental pulp stem cells/collagen sponge biocomplex in the treatment of non-contained intrabony defects: a case series. Clin Adv Periodontics 2015;5:104-9.

108. Li YE, Zhao S, Nan XI, Wei H, Shi J, et al. Repair of human periodontal bone de- fects by autologous grafting stem cells derived from inflammatory dental pulp tissues. Stem Cell Res Ther 2016;7:141. 
109. Aimetti M, Ferrarotti F, Gamba MN, Giraudi M, Romano F. Regenerative treatment of periodontal intrabony defects using autologous dental pulp stem cells: a 1-year follow-up case series. Int J Periodontics Restorative Dent 2018;38:51-8.

110. d'Aquino R, De Rosa A, Lanza V, Tirino V, Laino L, et al. Human mandible bone defect repair by the grafting of dental pulp stem/ progenitor cells and collagen sponge biocomplexes. Eur Cell Mater 2009;18:75-83.

111. Monti M, Graziano A, Rizzo S, Perotti C, Fante CD, et al. In vitro and in vivo differentiation of progenitor stem cells obtained after mechanical digestion of human dental pulp. J Cell Physiol 2017;232:548-55.

112. Akbay A, Baran C, Günhan O, Ozmeriç N, Baloş K. Periodontal regenerative potential of autogenous periodontal ligament grafts in Class II furcation defects. J Periodontol 2005;76:595-604.

113. Feng F, Akiyama K, Liu Y, Wang TM, Chen JH, et al. Utility of PDL progenitors for in vivo tissue regeneration: a report of 3 cases. Oral Dis 2010;16:20-8.

114. Kl V, Ryana H, Dalvi PJ. Autologous periodontal stem cell assistance in periodontal regeneration technique (SAI-PRT) in the treatment of periodontal intrabony defects: A case report with one-year follow-up. J Dent Res Dent Clin Dent Prospects 2017;11:123-6.

115. Koo S, Alshihri A, Karimbux NY, Maksoud M. Cellular allograft in the treatment of a severe periodontal intrabony defect: a case report. Clinic Adv Periodontics 2012;2:35-9.

116. McAllister BS. Stem cell-containing allograft matrix enhances periodontal regeneration: case presentations. Int J Periodontics Restorative Dent 2011;31:149-55.

117. Yamada Y, Ueda M, Hibi H, Baba S. A novel approach to periodontal tissue regeneration with mesenchymal stem cells and platelet-rich plasma using tissue engineering technology: a clinical case report. Int J Periodontics Restorative Dent 2006;26:363-9.

118. Yamada Y, Hara K, Nakamura S, Ueda M, Ito K, et al. Minimally invasive approach with tissue engineering for severe alveolar bone atrophy case. Int J Oral Maxillofac Surg 2013;42:260-3.

119. Rosen PS. A case report on combination therapy using a composite allograft containing mesenchymal cells with an amnion-chorion barrier to treat a mandibular class III furcation. Clin Adv Periodontics 2013;3:64-9.

120. Chen FM, Gao LN, Tian BM, Zhang XY, Zhang YJ, et al. Treatment of periodontal intrabony defects using autologous periodontal ligament stem cells: a randomized clinical trial. Stem Cell Res Ther 2016;7:33.

121. Shalini HS, Vandana KL. Direct application of autologous periodontal ligament stem cell niche in treatment of periodontal osseous defects: a randomized controlled trial. J Indian Soc Periodontol 2018;22:503-12.

122. Ferrarotti F, Romano F, Gamba MN, Quirico A, Giraudi M, et al. Human intrabony defect regeneration with micrografts containing dental pulp stem cells: a randomized controlled clinical trial. J Clin Periodontol 2018;45:841-50.

123. Dhote R, Charde P, Bhongade M, Rao J. Stem cells cultured on beta tricalcium phosphate (beta-TCP) in combination with recombinant human platelet-derived growth factor - BB (rh-PDGF-BB) for the treatment of human infrabony defects. J Stem Cells 2015;10:243-54.

124. Ledesma-Martínez E, Mendoza-Núñez VM, Santiago-Osorio E. Mesenchymal stem cells for periodontal tissue regeneration in elderly patients. J Gerontol A Biol Sci Med Sci 2019;74:1351-8.

125. Cho YD, Kim KH, Ryoo HM, Lee YM, Ku Y, et al. Recent advances of useful cell sources in the periodontal regeneration. Curr Stem Cell Res Ther 2019;14:3-8.

126. Hynes K, Menicanin D, Han J, Marino V, Mrozik K, et al. Mesenchymal stem cells from iPS cells facilitate periodontal regeneration. J Dent Res 2013;92:833-9.

127. Cai X, Yang F, Yan X, Yang W, Yu N, et al. Influence of bone marrow-derived mesenchymal stem cells pre-implantation differentiation approach on periodontal regeneration in vivo. J Clin Periodontol 2015;42:380-9.

128. Wen Y, Wang F, Zhang W, Li Y, Yu M, et al. Application of induced pluripotent stem cells in generation of a tissue-engineered tooth-like structure. Tissue Eng Part A 2012;18:1677-85.

129. Hynes K, Menichanin D, Bright R, Ivanovski S, Hutmacher DW, et al. Induced pluripotent stem cells: a new frontier for stem cells in dentistry. J Dent Res 2015;94:1508-15.

130. Pacelli S, Basu S, Whitlow J, Chakravarti A, Acosta F, et al. Strategies to develop endogenous stem cell-recruiting bioactive materials for tissue repair and regeneration. Adv Drug Deliv Rev 2017;120:50-70.

131. Lee K, Silva EA, Mooney DJ. Growth factor delivery-based tissue engineering: general approaches and a review of recent developments. J R Soc Interface 2011;8:153-70.

132. Cai X, Yang F, Walboomers XF, Wang Y, Jansen JA, et al. Periodontal regeneration via chemoattractive constructs. J Clin Periodontol 2018;45:851-60.

133. Miron RJ, Zhang Y. Autologous liquid platelet rich fibrin: a novel drug delivery system. Acta Biomater 2018;75:35-51.

134. Miron RJ, Zucchelli G, Pikos MA, Salama M, Lee S, et al. Use of platelet-rich fibrin in regenerative dentistry: a systematic review. Clin Oral Investig 2017;21:1913-27.

135. Park CH, Kim KH, Lee YM, Seol YJ. Advanced engineering strategies for periodontal complex regeneration. Materials (Basel) 2016;9:57.

136. Park CH, Rios HF, Taut AD, Miguel MP, Flanagan CL, et al. Image-based, fiber guiding scaffolds: a platform for regenerating tissue interfaces. Tissue Eng Part C Methods 2014;20:533-42.

137. Lee S, Choi E, Cha MJ, Hwang KC. Cell adhesion and long-term survival of transplanted mesenchymal stem cells: a prerequisite for cell therapy. Oxid Med Cell Longev 2015;2015:632902.

138. Hu L, Liu Y, Wang S. Stem cell-based tooth and periodontal regeneration. Oral Dis 2018;24:696-705.

139. Ozasa M, Sawada K, Iwayama T, Yamamoto S, Morimoto C, et al. Murakami, periodontal tissue regeneration by transplantation of adipose tissue-derived multi-lineage progenitor cells. Inflamm Regen 2014;34:109-16.

140. Liu Y, Zheng Y, Ding G, Fang D, Zhang C, et al. Periodontal ligament stem cell-mediated treatment for periodontitis in miniature swine. Inflamm Regen 2008;26:1065-73. 